Volume V JUNE, $1913 \quad$ PART III

\title{
FACTORS AFFECTING SUSCEPTIBILITY TO DISEASE IN PLANTS.
}

\section{Part I.}

\author{
By G. T. SPINKS, B.A., \\ Trinity Hall, Cambridge, Development Grant Research Scholar.
}

THE problem of immunity to disease in plants is now receiving a large amount of attention from plant-pathologists. It has long been known that different varieties of the same species of plant may differ in their susceptibility to the attacks of fungi and possibly other parasites, but even now practically nothing is known of the factors which determine whether a plant will prove immune to a disease or not. The following paper is a record of investigations which it was hoped would contribute something towards the solution of this problem, or which might at least suggest lines of further research on this subject.

It was thought that the simplest method of starting an attack on this question was by finding what effect the nutrition of a plant had on its susceptibility to disease. There has long been a general impression that heavy manuring makes plants more liable to disease, but hitherto no definite data have been available nor any detailed experiments made.

From experiments on the effect of mineral starvation on Bromes Marshall Ward' ${ }^{1}$ concluded that decreased susceptibility to rust was only caused by the lack of sufficient food in the host plant on which the rust fungus could feed, i.e. that the host was just as susceptible as under normal conditions but could not supply food to so large a quantity of the rust fungus. Later, histological examinations also showed that fungal hyphae in an immune plant were adversely affected in the same way as in a starved susceptible plant?.

1 M. Ward, Proc. Roy. Soc. 71, $1903 . \quad$ M. Ward, Ann. Bot. 19, 1905.

Journ. of Agric. Sci. $v$ 
These seemed to be the only records of any investigations on the effect of nutrition on immunity to disease in the higher plants. It was therefore decided to grow numbers of wheat plants under varying conditions of nutrition and to observe any differences in their susceptibility to the attacks of disease.

'The first set of experiments was performed with a number of wheat plants grown in water-cultures. The wheat grains were germinated on damp blotting-paper and were transferred, when the plumules were about an inch long, to the water-cultures. The young plants were supported in split corks in the necks of the bottles which had a capacity of about 300 c.c.

Throughout the experiments the bottles were filled up with tapwater on alternate days to replace the water lost by transpiration: the solution was left in the bottles for ten days without any attention except the filling-up above mentioned, and was then poured out and replaced by clean tap-water. After two days the bottles were filled with fresh nutrient solutions. These operations were repeated throughout the experiment, so that the plants received fresh solutions every twelve days but were in tap-water only for the last two days of each twelve-day period. It should be mentioned that the plants grew exceedingly well under these conditions and were indeed remarkable for their strong growth and extensive tillering. All the bottles received the same standard nutrient solution but to different series were-added various small amounts of strong solutions of different salts. The standard solution employed was the one used by Detmer and made up as follows :

Calcium nitrate

Potassium chloride

Magnesium sulphate

Potassium dihydrogen phosphate $\cdot 25 \mathrm{gm}$.

Ferric chloride

Tap-water
$1 \mathrm{gm}$.

$.25 \mathrm{gm}$.

$25 \mathrm{gm}$.

a few drops of solution.

1000 c.c.

Fifteen series of cultures were grown, each series consisting of three plants of a variety of wheat highly susceptible to Puccinia glumarum (Michigan Bronze) and three of a variety almost immune to the attacks of this fungus (Little Joss).

Series 1 was supplied with the normal nutrient solution, the 300 c.c. of solution which was placed in each bottle containing $051 \mathrm{gm}$. nitrogen in the form of nitrate, $017 \mathrm{gm}$. phosphorus as phosphate, and $06 \mathrm{gm}$. 
potassium. In series 2 the amount of nitrogen was doubled by adding $\cdot 3 \mathrm{gm}$. sodium nitrate, containing $\cdot 051 \mathrm{gm}$. nitrogen, to the solution in each bottle, while in series 3 the amount of nitrogen was increased to four times the normal by adding $9 \mathrm{gm}$. sodium nitrate. The next two series, 4 and 5 , also contained double and four times the normal amount of nitrogen, but in this case the additional nitrogen was contained in $24 \mathrm{gm}$. and $72 \mathrm{gm}$. of ammonium sulphate respectively. To series 6 and 7 was added sodium phosphate, the addition of $077 \mathrm{gm}$. containing $.017 \mathrm{gm}$. phosphorus doubling the phosphorus in series 6 , and of $2.3 \mathrm{gm}$. making the phosphate four times the normal in 7 . Similarly the potassium in series 8 and 9 was increased to twice and four times the normal by adding $\cdot 115 \mathrm{gm}$. and $345 \mathrm{gm}$. of potassium chloride, that is .06 and $\cdot 18 \mathrm{gm}$. potassium, to series 8 and 9 respectively. Series 10 and 11 received only the normal solution but the concentration in 10 was double, and in 11 four times the normal concentration. On the other hand series 12 and 13 received the normal solution diluted to one half and one quarter the original concentration. Series 14 and 15 received an addition of both potassium and phosphate; in the first case the potash and phosphate were both brought to twice the normal, and in the second case to four times.

The seedlings were placed in the water-cultures on Feb. 28 in the cuse of the series $1-9$, and a week later in the case of the remaining series, the whole set of cultures being grown close together in the same greenhouse.

As may be deduced from the varieties of wheat selected, it was originally intended to inoculate the plants with Puccinia glumarum, but as late as April 24, it had been found impossible to obtain enough to infect the plants. Only a very small quantity of this fungus was obtaived on April 24 and a few inoculations were made, but these proved to be failures. In the meantime a spontaneous outbreak of Erysiphe graminis had occurred among the plants, so it was resolved to study the attack of this parasite iustead of that of Puccinia glumarum. Accordingly the spread of the mildew was encouraged by putting the plants close together and keeping the atmosphere in the greenhouse damp. Also, the relative positions of the plants were frequently changed so as to give the healthy every opportunity of being attacked, and at the same time to eliminate any differences due to the outside plants receiving more air and light.

On April 24, all the plants were examined and marks were awarded to each in proportion to the amount of mildew present, those with only 
a trace of mildew being marked 1 and those which were most severely attacked being marked 10. This examination and marking was repeated on May 3 and for the third and last time on May 15. By this time the most badly attacked plants were covered all over with a thick coating of mildew and were practically dead: their condition can be seen from the photograph in Plate VII, Fig. 1. The least diseased plants only showed a few patches of mildew and their leaves were strong and of a good green colour, contrasting very strongly with the dingy flaccid leaves of the badly diseased plants. Fig. 2, Plate VII, shows one of the healthiest plants.

It must be remembered that these comparatively healthy plants had been surrounded by, and actually in contact with, the badly diseased ones for several weeks and had thus had every opportunity of succumbing to the attack of the parasite. Most of the plants grew to about the same size, the exceptions being in the series $5,11,12$ and 13 .

The plants in series 5 , which received a large addition of ammonium sulphate, were of the average size as regards their leaves but their root-systems were distinctly poor. The plants growing in the concentrated solution in series 11 were rather smaller and their roots were rather below the average size. The plants which grew in solutions more dilute than the normal (12 and 13) were small but had welldeveloped roots.

The intensity of disease increased on all the plants between the first and last occasion of marking, but as the relative positions of the plants in the scheme of marking were practically constant only the final markings are given here.

Table I shows the marks which indicate the amount of disease on each of the 90 plants at the conclusion of the experiment.

It will be seen from the preceding table that the nutrient solutions in which the plants were growing exercised a very large influence on their susceptibility to disease, and that the different degrees in which the plants became diseased was not accidental but can be correlated with the treatment they received. In the first place it will be noted that although one variety of wheat was more susceptible to disease than the other, yet the effect due to the different solutions follows almost the same relative order in both varieties. In both cases series $2,3,4$ and 5 which received additional nitrogen contained the must badly diseased plants (Plate VII, Fig. 3), though it is curious that the plants of No. 5 receiving four times the normal amount of nitrogen as ammonium sulphate were not so badly attacked as those of No. 4 which only 


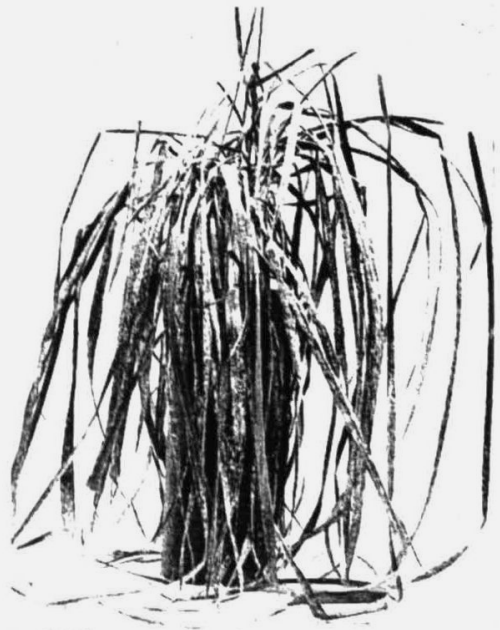

Fig. 1.

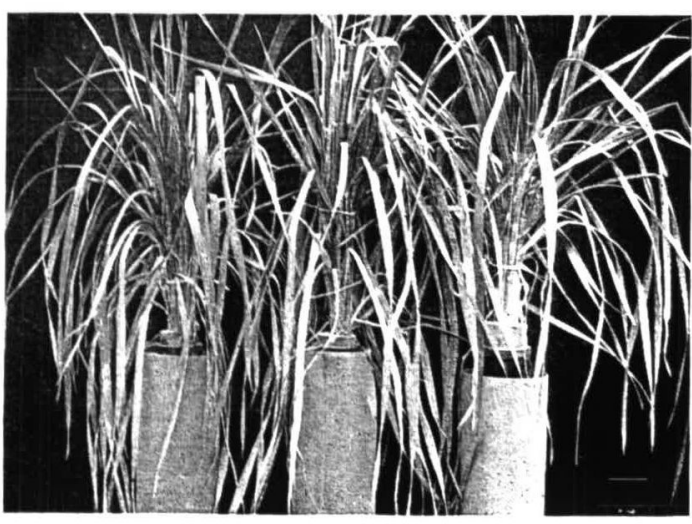

Fig. 3.

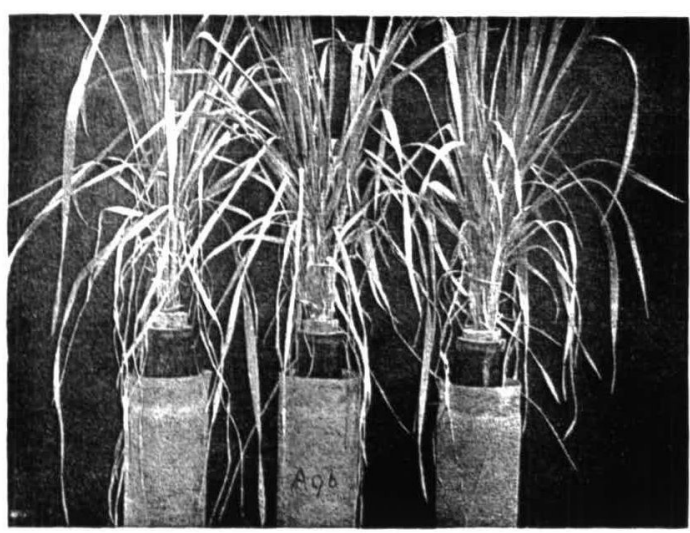

Fig. 5.

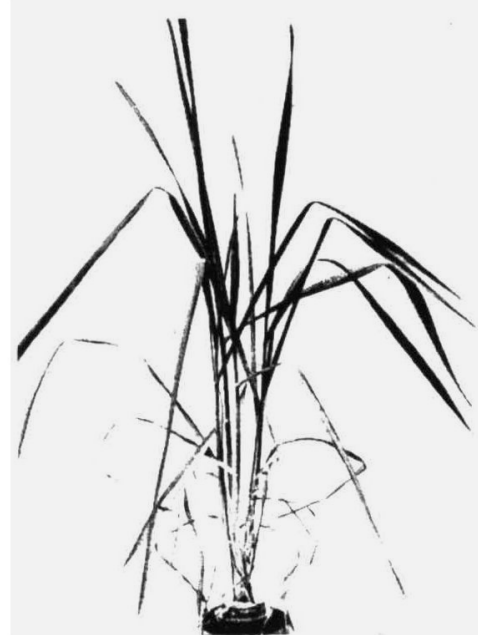

Fig. 2.

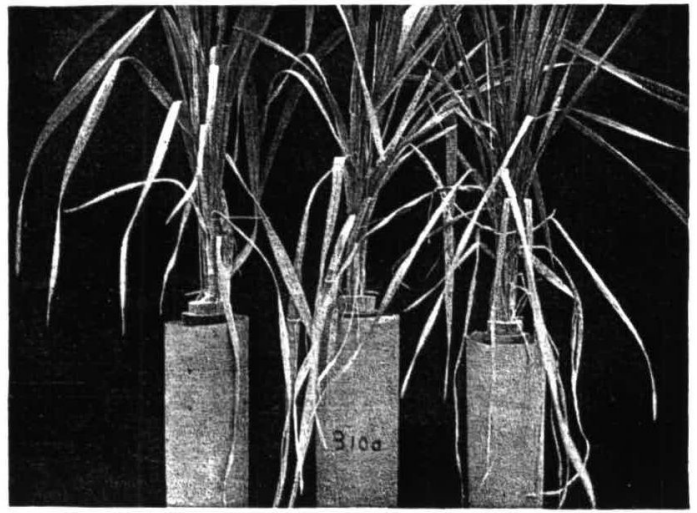

Fig. 4.

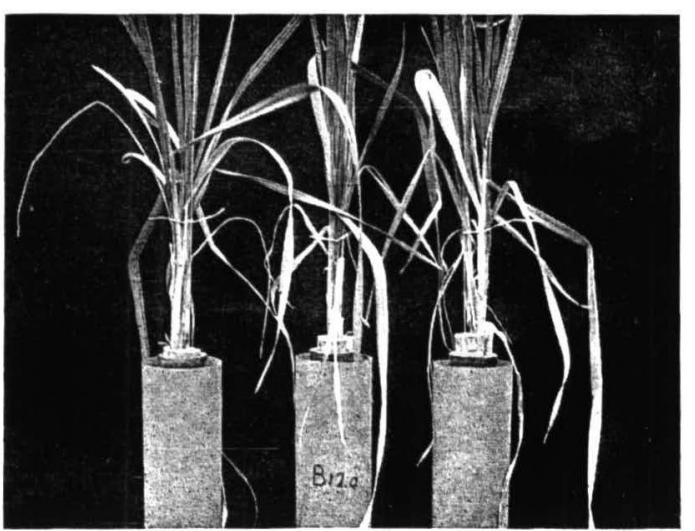

Fig. 6. 
received twice the normal amount of nitrogen: perhaps there is some connection between this fact and the stunted root-growth noticed in series 5 .

TABLE I.

\begin{tabular}{|c|c|c|c|c|c|c|c|}
\hline \multirow{2}{*}{ No. } & \multirow{2}{*}{ Solution } & \multicolumn{6}{|c|}{ Degree of disease } \\
\hline & & \multicolumn{3}{|c|}{ Little Joss (3 plants) } & \multicolumn{3}{|c|}{$\begin{array}{l}\text { Michigan Bronze } \\
\text { (3 plants) }\end{array}$} \\
\hline $\begin{array}{r}1 \\
2 \\
3 \\
4 \\
5 \\
6 \\
7 \\
8 \\
9 \\
10 \\
11 \\
12 \\
13 \\
14 \\
15\end{array}$ & 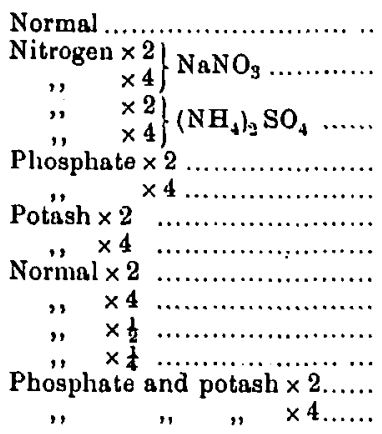 & $\begin{array}{r}9 \\
9 \\
10 \\
10 \\
8 \\
6 \\
7 \\
7 \\
5 \\
9 \\
9 \\
7 \\
7 \\
7 \\
7\end{array}$ & $\begin{array}{r}7 \\
9 \\
10 \\
10 \\
8 \\
6 \\
7 \\
5 \\
5 \\
9 \\
8 \\
7 \\
5 \\
7 \\
4\end{array}$ & $\begin{array}{r}7 \\
9 \\
8 \\
10 \\
8 \\
4 \\
7 \\
4 \\
3 \\
9 \\
8 \\
5 \\
5 \\
7 \\
4\end{array}$ & $\begin{array}{r}10 \\
10 \\
10 \\
9 \\
8 \\
6 \\
5 \\
5 \\
3 \\
9 \\
5 \\
1 \\
1 \\
5 \\
7\end{array}$ & $\begin{array}{l}5 \\
7 \\
7 \\
9 \\
8 \\
5 \\
5 \\
5 \\
3 \\
7 \\
5 \\
1 \\
1 \\
3 \\
5\end{array}$ & $\begin{array}{l}5 \\
7 \\
5 \\
9 \\
5 \\
5 \\
2 \\
2 \\
3 \\
7 \\
5 \\
1 \\
1 \\
3 \\
5\end{array}$ \\
\hline
\end{tabular}

Next, the plants receiving a concentrated nutrient solution were observed to be badly diseased, but here again the extremely strong solution in series 11 has checked the growth of the plants to some extent, and at the same time there is less disease than in the plants of No. 10 (Plate VII, Fig. 4).

Series 6 and 7 receiving additional phosphate showed about the average amount of disease, or possibly rather less. The series 8 and 9 which received additional potash were very clearly rendered less susceptible to disease : in the case of Little Joss the plants of Nos. 8 and 9 were the healthiest of the whole set (Plate VII, Fig. 5), while among the Michigan Bronzes they were the healthiest with the exception of those of series 12 and 13 .

The plants receiving additional phosphate and potash (14 and 15) seemed to be intermediate in their susceptibility between those receiving only phosphate or only potash.

The plants growing in dilute solutions (12 and 13) were healthier than the normal, and indeed in the case of the Michigan Bronzes they were the healthiest of the set (Plate VII, Fig. 6): in both varieties the plants of series 13 were slightly less diseased than those of 12 ; that is, the disease was reduced when the food supply was reduced. 
While the above-mentioned water-cultures were in progress a parallel series of experiments was being made on wheats grown in soil.

A number of wooden boxes about 17 inches $\times 13$ inches were filled to a depth of $2 \frac{1}{2}$ inches with rather poor soil which was obtained by mixing a rather rich soil, obtained from the neighbourhood of the laboratory, with about an equal bulk of sand. In one box the soil was made still poorer by doubling the amount of sand.

On March 12 twelve grains of Little Joss were sown in each box and twelve of Michigan Bronze, two rows of each variety in each box : on the average eleven grains of each variety produced plants. The boxes were all in the same greenhouse near the water-cultures, so that the plants were very readily naturally infected by the mildew, and in this case also the position of the boxes was often changed in order to make the conditions as far as possible equal for all.

Au attempt was made to add artificial manures to the boxes in amounts comparable to those used in practice in the field. It was calculated that the area of a box was $1 \frac{1}{2}$ square feet or $\frac{1}{30,000}$ acre and that 1.7 grams per box would be equivalent to $1 \mathrm{cwt}$. per acre. The quantities of fertilisers applied are given in Table II which also records the results. The salts to be added were made into solutions and it was intended to apply these solutions in six doses at intervals of a fortnight, but the experiment was brought to an end when only four of these doses had been applied. This explains the fractions in the amounts of fertiliser applied; thus $1.33 \mathrm{cw}$. was originally intended to have been increased to $2 \mathrm{cwt}$., and so on.

The plants in all the boxes grew almost equally well, but before the mildew had attacked them seriously those which received nitrogenous manures were larger and of a darker colour than the rest: on the other hand the plants in the "starvation" box were small, thin and lightcoloured. As in the case of the water-cultures the boxes were examined and graded according to the amount of mildew present on May 4, 15 and 20 , but as the relative amounts were constant only the last set of marks is given here. The plants in each box were not marked individually, as the individuals of the same variety in the same box showed no differences, but the two varieties in each box were judged separately.

The extent of the disease on the plants in each box is shown in Table II.

It will be seen that the order of the severity of the attack of mildew in the different boxes was the same for both varieties of wheat. 
The plants in box 5 receiving a double dressing of sodium nitrate were the most severely attacked in both cases, while all the other boxes which received nitrogenous manures showed a very bad attack. The least susceptible plants were those in box 9 , which received a double dose of sodium phosphate, while those in 10 and 11 which received potassium chloride were only slightly attacked, the same being the case in box 14 where the plants were almost starved.

Table II.

\begin{tabular}{|c|c|c|c|}
\hline \multirow{2}{*}{ No. } & \multirow{2}{*}{ Treatmeut } & \multicolumn{2}{|c|}{ Degree of disease } \\
\hline & & $\begin{array}{c}\text { Little } \\
\text { Joss }\end{array}$ & $\begin{array}{c}\text { Michigan } \\
\text { Bronze }\end{array}$ \\
\hline 1 & No manure & 7 & 5 \\
\hline 2 & 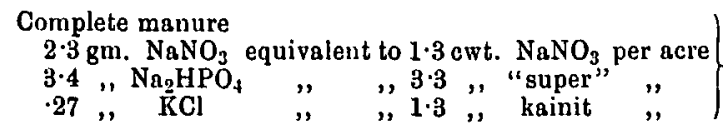 & 9 & 7 \\
\hline $\mathbf{3}$ & Complete manure. Double the above quantities........... & 9 & 7 \\
\hline 4 & $2.3 \mathrm{gm} . \mathrm{NaNO}_{3}$ equivalent to $1.3 \mathrm{cwt}$. $\mathrm{NaNO}_{3}$ per acre...... & 8 & 6 \\
\hline 5 & $4.6 \mathrm{gm} . \mathrm{NaNO}_{3}$ equivalent to $2.6 \mathrm{cwt} . \mathrm{NaNO}_{3}$ per acre..... & 10 & 8 \\
\hline 6 & $1.8 \mathrm{gm}$. $\left(\mathrm{NH}_{4}\right)_{2} \mathrm{SO}_{4}$ equivalent to $1 \mathrm{cwt} .\left(\mathrm{NH}_{4}\right)_{2} \mathrm{SO}_{4}$ per acre & 8 & 6 \\
\hline 7 & $3.6 \mathrm{gm} .\left(\mathrm{NH}_{4}\right)_{2} \mathrm{SO}_{4}$ equivalent to $2 \mathrm{cwt} .\left(\mathrm{NH}_{4}\right)_{2} \mathrm{SO}_{4}$ per acre & 9 & 7 \\
\hline 8 & $3.4 \mathrm{gm} . \mathrm{Na}_{2} \mathrm{HPO}_{4}$ equivalent to $3.3 \mathrm{cwt}$. "super" per acre & 6 & 4 \\
\hline 9 & $6.8 \mathrm{gm} . \mathrm{Na}_{2} \mathrm{HPO}_{4}$ equivalent to $6.6 \mathrm{cwt}$. "super" per acre & 3 & 1 \\
\hline 10 & $\cdot 27 \mathrm{gm}$. KCl equivalent to $1.3 \mathrm{cwt}$. kainit per acre .......... & 4 & 2 \\
\hline 11 & $54 \mathrm{gm} . \mathrm{KCl}$ equivalent to $2.6 \mathrm{cwt}$. kainit per acre ......... & 5 & 3 \\
\hline 12 & $\begin{array}{l}3.4 \mathrm{gm} . \mathrm{Na}_{2} \mathrm{EPO}_{4} \text { equivalent to } 3.3 \text { cwt. "super" per acre) } \\
.27, \mathrm{KCl}=1.3, \text { kainit ", }\end{array}$ & 7 & $\mathbf{5}$ \\
\hline 13 & 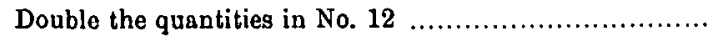 & 6 & 4 \\
\hline 14 & No manure. Double the quantity of sand & 5 & $\mathbf{3}$ \\
\hline
\end{tabular}

A single dressing of sodium phosphate seems to be less useful in preventing disease than a single dressing of potassium chloride, but if the dose be doubled the result is reversed.

A mixture of sodium phosphate and potassium chloride also seems to be rather less effective than either of these substances separately. 
On the whole these results agree very closely with those obtained from the water-cultures, though phosphates appear to be more effective in checking disease when the plants are grown in soil than when grown in water-cultures.

Two more sets of wheat-cultures were carried out in a similar manner to the preceding ones in order to find the effect of nutrition on the susceptibility of the plants to yellow rust, Puccinia glumarum.

The first of these was a set of water-cultures in which the same varieties of wheat as before were used, but a much smaller number were employed. In this case only those culture solutions were used which had been found to give extreme results in the first investigation, together with one of the so-called normal solutions as a control. There were then three series of cultures, each consisting of three plants of each variety, and they were treated in identically the same way as the corresponding cultures of the former set. The only difference was that this set of cultures was carried out in the open air as far from the greenhouse as possible in order to avoid infection by the mildew: but it was found impossible to keep them free from the mildew, though they were not nearly so badly attacked as those on which this parasite had been encouraged.

The plants of series 1 received the normal solution (cf. series 1 of former set); those of series 2 had the amount of nitrogen in the solution doubled by the addition of ammonium sulphate (cf. series 4 above), and those of series 3 were grown in a solution containing four times the normal amount of potash (cf. series 9).

On May 23 the seedling wheats were placed in the water-cultures and on May 28 when each showed two leaves they were inoculated with uredospores of Puccinia glumarum. The inoculations were made by scraping a "rusty" leaf of wheat with a wet penknife-blade and then applying the blade to the tips of the leaves to be infected; the leaf-tips were first made moist by blowing on to them through a narrow glass tube which caused the water containing the spores to adhere more readily to the leaf. On June 6 more inoculations were made, but this time on the middle of the upper surface of the leaf-blades: there were at this time three or four leaves on each plant.

On June 10 rust pustules appeared on one plant on an inoculated spot, and on June 12 eight plants showed pustules. From this date the disease spread rapidly without any artificial assistance other than that of placing the plants very close together so that the rusty leaves could touch the healthy ones. 
The plants were graded for rust on July 1 and it is interesting to note that at this time all the plants showed rust pustules, though the Little Joss, which is almost immune, had the disease to a very much less extent than the Michigan Bronze. On July 12 the plants were again marked for the rust attack and the marks are sbown in Table III.

TABLE III.

\begin{tabular}{|c|c|c|c|c|c|c|c|}
\hline \multirow{3}{*}{ No. } & \multirow{2}{*}{ Solution } & \multicolumn{6}{|c|}{ Degree of rust } \\
\hline & & \multicolumn{3}{|c|}{ Little Joss } & \multicolumn{3}{|c|}{ Michigan Bronze } \\
\hline & Normal ................... & 0 & 0 & 0 & 8 & 6 & 5 \\
\hline 2 & Nitrogen $\times 2$ (Amm. sulph.) ........ & 0 & 3 & 3 & $y$ & 9 & 8 \\
\hline 3 & Potasb $\times 4$ & 0 & 0 & 2 & 6 & 5 & 3 \\
\hline
\end{tabular}

It will be seen that only three out of the nine plants of the relatively immune variety showed any rust at this stage, and of these two were those which had received solutions with double nitrogen. With one exception all the Michigan Bronze plants were much more diseased than any of the other variety, and it will be seen that the attack on series 2 was much worse than that on 1, while on series 3 it was slightly less. By this time all the plants of the first variety were suffering severely from mildew, so they were thrown away: but the plants of the other variety were kept for a few weeks longer. On July 23 the remaining plants were again marked and found to occupy the same relative positions as in the previous marking. On Aug. 5 however the rust on the plants of series 1 and 2 was the same as on the previous occasion, while two of the plants in series 3 were much more severely attacked than before, earning marks 8 and 6 . Perhaps this can be accounted for by the fact that the plants of 1 and 2 were almost killed by mildew and so the rust had no chance to spread further, while plants of series 3 were still green and growing vigorously.

Observations were also made on the susceptibility to rust of a number of wheat plants grown in pots receiving different nutritive solutions. Fourteen series of 5 -inch pots were grown, each series consisting of one pot containing three plants of Little Joss and one containing three plants of Michigan Bronze. The amounts of manurial substances to be added to the various pots were calculated on the same 
system as was employed in the case of the boxes. As before, a soil mixed with about an equal amount of sand was used in all the pots.

The fourteen series of pots were treated in the following ways: No. 1 was a control receiving no manure; Nos. 2, 3 and 4 received different quantities of a complete manure; Nos. 5 and 6 received respectively a single and double dose of sodium nitrate, while 7 and 8 were given the same amounts of nitrogen in the form of ammonium sulphate. To Nos. 9 and 10 were given single and double dressings of sodium phosphate, and Nos. 11 and 12 received similar treatment with potassium chloride. Nos. 13 and 14 received no manure, but were sterilised in a steamer at $100^{\circ} \mathrm{C}$. for two hours before the seeds were set. The manures used were equivalent to about 2 and 4 cwt. sodium nitrate per acre, $1 \frac{1}{2}$ and $3 \mathrm{cwt}$. ammonium sulphate, 5 and $10 \mathrm{cwt}$. superphosphate, and 2 and 4 cwt. kainit. The fertilisers in solution were added in three separate doses, an interval of about a fortnight occurring between the applications, and the first dressing was given about a week after sowing the seeds.

The seeds were sown in the pots on May 8 and by May 20 all the seeds had germinated and each seedling showed one or two leaves. Between May 18 and 23 every leaf on all the plants was inoculated with uredospores of Puccinia glumarum in the manner previously described. The first sign of successful infection was seen on May 28, when one leaf was found to bear some unbroken pustules on its tip: these pustules opened and set free their spores on the following day. More leaves gradually showed pustules until on June 5 the disease was evident on Little Joss plants in four pots, and on Michigan Bronze plants in eight pots. On June 6 another inoculation was made, this time on the middle of the upper surface of the leaves, about four leaves being inoculated in each pot.

By June 10 all the Michigan Bronze plants showed rust, while the disease had appeared on about half the Little Joss plants. From this date onward the disease spread rapidly and on July 1 the cultures were first graded according to the amount of rust present on each. At this time ten of the fourteen Little Joss cultures were marked 0 as being free from rust, while the remaining four were marked 1 or 2 , the disease attack being very slight. Among the Michigan Bronze cultures $9,10,11$ and 12 were the least diseased, all the others being almost equally bad, although perhaps 3,7 and 8 were the worst.

On July 10 the marks awarded were almost the same as before, but 
although there were again four plants of Little Joss showing degrees 1 or 2 of rust three of these were not included in the four on July 1.

The plants were again marked according to their rustiness on July 23, Aug. 5 and 13, but the disease was making no further progress and the relative amounts of rust on the various plants showed only small fluctuations which might almost be put down to errors in observation. The figures in Table IV may therefore be considered to represent the extent of the disease on the different cultures when the disease had attained its maximum development.

TABLE IV.

\begin{tabular}{|c|c|c|c|c|}
\hline \multirow{2}{*}{ No. } & \multirow{2}{*}{\multicolumn{2}{|c|}{ Manure equivalent per ncre }} & \multicolumn{2}{|c|}{ Extent of disease } \\
\hline & & & $\begin{array}{c}\text { Little } \\
\text { Joss }\end{array}$ & $\begin{array}{c}\text { Michigan } \\
\text { Bronze }\end{array}$ \\
\hline 1 & None . & …................... & 0 & 6 \\
\hline 2 & $\begin{array}{ll}1 & \text { ewt } \\
2 \frac{1}{2} & ", \\
1 & ",\end{array}$ & $\left.\begin{array}{l}\text { t. sodium nitrate } \\
\text { " super" } \\
\text { kainit }\end{array}\right\} \ldots$ & 1 & 7 \\
\hline 3 & $\begin{array}{ll}2 & \prime \\
5 & \prime \prime \\
2 & " \prime\end{array}$ & $\left.\begin{array}{l|l} & \left.\begin{array}{l}\text { sodium nitrate } \\
\text { " }\end{array}\right\} \text { kaper" } \\
\end{array}\right\}$ & 1 & 7 \\
\hline 4 & $\begin{array}{rl}4 & " \\
10 & " \\
4 & ",\end{array}$ & $\left.\begin{array}{l}\text { sodium nitrate } \\
\text { " } \text { kaper" }\end{array}\right\} \ldots$ & 1 & 7 \\
\hline 5 & $2 \quad "$ & , sodium nitrate ...... & 1 & 7 \\
\hline 6 & 4. " & , , , $\quad, \quad \ldots .$. & 1 & 7 \\
\hline 7 & $1 \frac{1}{2} \quad$, & , ammonium sulpliate & 1 & 7 \\
\hline 8 & $n$ & , $\quad$ " & 1 & 9 \\
\hline 9 & ", & , " super" '.............. & 1 & 5 \\
\hline 10 & $10 \quad "$ & $, \quad, \quad \ldots \ldots \ldots \ldots \ldots$ & 1 & 6 \\
\hline 11 & ", & , lkainit ................. & 1 & 5 \\
\hline 12 & $4 \quad$, & , $\quad, \quad$, $\quad \ldots \ldots \ldots \ldots \ldots$ & 1 & 4 \\
\hline 13 & None. & Soil sterilised ........ & 1 & 7 \\
\hline 14 & $"$ & $" \quad, \quad \ldots \ldots \ldots$ & 1 & 7 \\
\hline
\end{tabular}

At first it was thought that only two or three of the Little Joss cultures showed any sign of disease, but a very careful scrutiny revealed 
minute traces, perhaps three or four unbroken pustules, on each culture except No. 1. It was noted that these pustules always appeared on leaves which were almost dead, and which therefore apparently had not quite the same power of resisting the disease that a leaf in full vigour possesses. This wheat then was so nearly immune to the disease under all the conditions of the experiment that no difference was perceptible between the various cultures.

The differences between the susceptibility of the various cultures of Michigan Bronze were not nearly so striking as they were in the experiment where mildew was used, but the marks in Table IV show that some differences existed. Nos. 11 and 12, receiving potash, were clearly the least diseased, though 9 and 10 which were treated with sodium phosphate were nearly as free from disease. All the cultures which received nitrogenous dressings were about equally diseased, except No. 8 which was considerably worse than any other. The cultures in the sterilised soil showed more disease than the control plants and were about equal to most of those to which nitrogen was given.

It was thought desirable to compare the preceding results with those obtained on a larger scale, and we were enabled to examine the field-plots on the farm of the Royal Agricultural Society at Woburn for this purpose. The pot-cultures at Woburn were also examined and gave some interesting results, though the treatments they had been receiring were quite different from those applied to any of our own cultures.

With regard to the pot-cultures, it was found that rust was practically absent, the amount present being so small that no idea of the susceptibility of the various cultures could be gained.

Table $\mathrm{V}$ shows the marks denoting the amount of mildew on the various wheat cultures and their mode of treatment.

It is seen from the above table that the severity of the attack on the control plants varied between 2 and 5 with an average of 3 to 4 . Only one of the cultures receiving basic slag was marked outside this range, while the average marks were about the same: the addition of basic slag seems therefore to have had no effect on the susceptibility of the plants to mildew. The plants grown in the soil containing magnesia showed a distinct increase of susceptibility to the disease (8) which was very little, if at all, decreased by the addition of lime. These plants were much greener and less mature than those of most of the cultures, which were beginning to ripen. It is possible that an increased 
susceptibility to the disease may be a result of the treatment delaying the growth of the plant: or the increased infection may be due to a rapid and vigorous growth of the plant late in the season following the check received in its young stages. It will be found that these conditions had occurred in the case of some of the other badly diseased plants.

Tabie V.

\begin{tabular}{|c|c|c|}
\hline Cultures & Treatment & Mildew \\
\hline 38 and 41 & $\begin{array}{l}\text { Control .... } \\
\text { Basic slay added in various ways }\end{array}$ & 4,5 \\
\hline $\begin{array}{l}56-63 \text { and } 68 \\
80-86 ; 96-100\end{array}$ & $\begin{array}{lllll} & , & " & & \end{array}$ & $\begin{array}{l}4,4,2,4,3,3,3,4,2 \\
3,1,3,4,4,3,5,4,2,2,4,4\end{array}$ \\
\hline $\begin{array}{c}50 \\
51-55\end{array}$ & $\begin{array}{l}\text { Soil containing } \mathrm{MgO} " \ldots \ldots \ldots \\
\text { (CaO added) } \ldots\end{array}$ & $\begin{array}{l}8,7,7,7,7 \\
8,7,7\end{array}$ \\
\hline 101 and 102 & 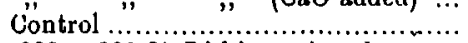 & 3,3 \\
\hline $\begin{array}{l}102-108 \\
109-114\end{array}$ & $\begin{array}{l}003-001 \% \text { Lithium phosphate } . . . \\
.03-01 \% \text { Zinc phosphate .. ............. }\end{array}$ & $\begin{array}{l}0,0,0,0,1,1 \\
4,4,5,4,5,4\end{array}$ \\
\hline $115,117,119$ & $\begin{array}{l}03-.01 \% \text { Lead } \\
\text { Control } \ldots \ldots \ldots \ldots \ldots\end{array}$ & $\begin{array}{l}3,3,3 \\
4\end{array}$ \\
\hline $\begin{array}{l}123,125,127 \\
129-134 \\
135-140\end{array}$ & $\begin{array}{l}.003-.001 \% \text { Lithium nitrate } . . . . . . . . \\
.03-.01 \% \text { Zine nitrate } \ldots \ldots \ldots \ldots \ldots \ldots . . .\end{array}$ & $\begin{array}{l}0,0,6 \\
9,10,10,10,10,10 \\
7,7,7,5,5,5\end{array}$ \\
\hline 141 and 142 & Control & 2,2 \\
\hline $\begin{array}{l}143-148 \\
149-154\end{array}$ & $.003-001 \%$ Lithium carbonate $\ldots$ & $0,0,1,0,1,1$ \\
\hline $\begin{array}{l}149-154 \\
155-160\end{array}$ & $.03-01 \%$ Zinc carbonate $. . . \ldots \ldots \ldots . . . . .$. & $\begin{array}{l}3,3,3,1,3,2 \\
3,1,3,1,1,1\end{array}$ \\
\hline
\end{tabular}

Turning now to the cultures to which lithium salts were applied a very marked beneficial effect was found (except in one case, where strange to say the degree of inildew was 6) the amount of disease was reduced to 1, or more often the disease was entirely absent. All the lithium salts used appeared to be equally effective in preventing the appearance of the disease, and in nearly every case an increase in the amount of the salt supplied produced an increased immunity.

The cultures treated with zinc salts showed interesting differences: those receiving zinc carbonate were slightly below the normal in the amount of disease, the phosphate increased the susceptibility slightly, while on those plants treated with zinc nitrate the disease was extremely bad and had almost killed the plants. The amount of zinc salt applied did not affect the amount of disease present. The plants treated with zinc nitrate were much shorter and less mature than other plants, and were said to have been very severely checked in the early stages of their growth; so it is possible that this, rather than any direct action of the zinc nitrate, may have been the cause of the increased disease attack. 
The lead salts also varied in their effects on the disease. The plants receiving the phosphate scarcely differed from the normal; the nitrate increased the disease distinctly but not as much as the zinc nitrate did; and the carbonate decreased the attack slightly. The amount of lead nitrate added produced corresponding variations in the amount of disease present. The carbonates of all the above metals seemed to diminish the susceptibility of the wheat slightly.

The field plots of wheat were unfortunately not examined until late in the season when the wheat was almost ripe; therefore in many cases it was extremely difficult to determine how much disease there had been, especially as regards mildew. Table VI shows the treatment the various plots had received and the amount of mildew and rust on them: where no figure is given for the mildew the wheat was so ripe that no trustworthy figures could be obtained.

TABLE VI.

\begin{tabular}{|c|c|c|c|}
\hline Plot & Manures applied annually per acre & Mildew & Rust \\
\hline 1 & Unmanured................................. & 1 & 1 \\
\hline $2 a$ & 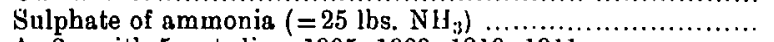 & - & - \\
\hline $2 a c$ & As $2 a$ with 5 cwt. lime $1905,1909,1910,1911 \ldots \ldots \ldots \ldots \ldots$ & 4 & 4 \\
\hline $2 b$ & 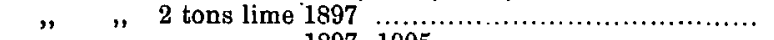 & 4 & 4 \\
\hline $2 b b$ & ", ", " & 6 & 5 \\
\hline $\begin{array}{l}3 a \\
\mathbf{3} b\end{array}$ & 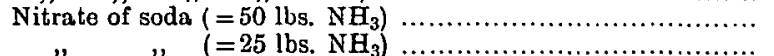 & $\begin{array}{r}8 \\
10\end{array}$ & 5 \\
\hline 4 & Minerals (3" cwt. "super" and $\left.\frac{1}{3} \mathrm{cwt} . \mathrm{K}_{2} \mathrm{SO}_{4}\right) \ldots \ldots$. & $\begin{array}{r}10 \\
0\end{array}$ & $\begin{array}{l}6 \\
0\end{array}$ \\
\hline $5 a$ & $" \quad$ and ammonium sulphate $\left(=25 \mathrm{lbs} . \mathrm{NH}_{3}\right)$ & 2 & 4 \\
\hline $5 b$ & 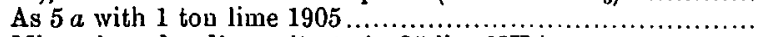 & 3 & 4 \\
\hline 6 & Minerals and sodium nitrate ( $=25$ lbs. $\mathrm{NH}_{3}$ ) & & $\mathbf{3}$ \\
\hline 7 & 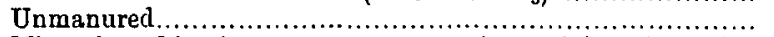 & 1 & 1 \\
\hline $8 a$ & $\begin{array}{l}\text { Minerals and in alternate years ammonium sulphate (=50 lbs. } \\
\left.\mathrm{NB}_{3}\right)(1911)\end{array}$ & & 6 \\
\hline $\begin{array}{l}8 a a \\
8 b \\
8 b b\end{array}$ & 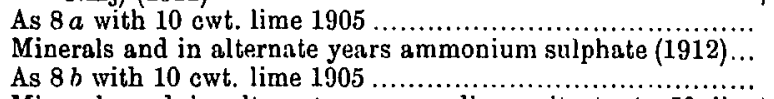 & & $\begin{array}{l}7 \\
6 \\
8\end{array}$ \\
\hline $9 a$ & $\begin{array}{l}\text { Minerals and in alternate years sodium nitrate (=50 lbs.) } \\
\left.\mathrm{NH}_{3}\right)(1911)\end{array}$ & & 4 \\
\hline $\begin{array}{r}9 b \\
10 a \\
10 b \\
11 a \\
11 b\end{array}$ & 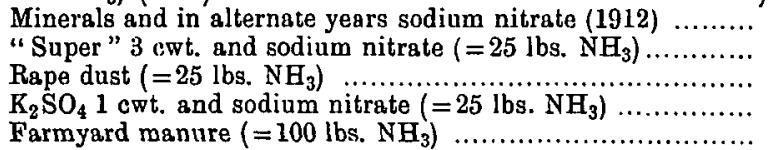 & & $\begin{array}{l}4 \\
2 \\
4 \\
2 \\
4\end{array}$ \\
\hline
\end{tabular}

It is perhaps unnecessary to explain that these plots have been growing wheat and have received the same treatment continuously for over thirty years. The wheat grown this year was Square Head's Master. 
From the figures available for the mildew it is seen that the unmanured plots 1 and 7 , and plot 4 which receives mineral manures only, were practically free from mildew. The crops on these plots were, of course, very thin and short. The ammonium sulphate plots $2 a a, 2 b$ and $2 b b$ showed a medium amount of mildew, but the plots on which the disease was worst were Nos. $3 a$ and $3 b$ which receive only nitrate of soda. The plants here were of only medium size, not at all luxuriant in their foliage.

The figures for the mildew cannot be considered to be at all accurate, but the two extremes were clearly enough marked, 1,7 and 4 on the one hand and $3 a$ and $3 b$ on the other.

The marks for the rust are more to be depended on, and on examining them it is first noticed that the same plots 1,7 and 4 were again almost disease-free. From the rest of the figures very little is to be gathered: on plots $8 a$ to $8 b b$ the addition of minerals to the ammonium sulphate seems to have increased the tendency to disease as compared with plots $2 a a$ to $2 b b$ which received ammonium sulphate without mineral manures: on the other hand no increased disease was noted on plots $5 a$ and $5 b$. Addition of minerals to sodium nitrate on the contrary seems to have decreased the anount of disease, as may be seen by comparing plots $6,9 a, 9 b, 10 a$ and $11 a$ with plots $3 a$ and $3 b$. The dunged plot showed about an average amount of rust.

The field plots of barley were much less advanced than the wheat and showed the different degrees to which they had been attacked by mildew very plainly. On two or three of the plots a small amount of Puccinia graminis was found, but it was not at all common so no marks were given for the rust attack. The barley plots have received almost exactly parallel treatment to that of the wheat plots except that plots $2 b, 5 b, 8 a a$ and $8 b b$ were given another dressing of lime this year: also $5 a$ is divided into $5 a$ and $5 a a$, the latter having received a dressing of lime in 1905. The variety of barley grown this year was Goldthorpe. The marks assigned for the amount of mildew on the barley plots are given in Table VII.

Plots 1 and 4, as we should have expected from our previous experience, were two of the least diseased; but it is at first surprising to find that No. $9 a$, which received a large dressing of nitrate of soda the previous year in addition to minerals, showed so little disease. In all probability the soluble nitrates had been completely washed out of the porous Woburn soil. The small amount of mildew on the dunged plot is also rather strange, especially as the plants were growing 
luxuriantly. The disease was worst on plots $3 a$ and $3 b$ which received sodium nitrate only, and then on the 8's, which were manured with minerals and ammonium sulphate. The 8's are worse than the 2's which received ammonium sulphate only; but the 5 's which also received ammonium sulphate and minerals were only slightly worse than the average. Plots 6 and $9 b$, which were both dressed with sodium nitrate and minerals, showed about the average amount of disease. Where plots received a nitrogenous dressing only in alternate years it was seen that the mildew was worse on the plots which received a dressing this year than on those which were manured in the previous year: cf. $9 a$ and $9 b$; $s a a$ and $8 b b$.

TABLE VII.

\begin{tabular}{|c|c|c|}
\hline No. & Manures applied annually per acre & $\begin{array}{l}\text { Extent of } \\
\text { mildew }\end{array}$ \\
\hline 1 & Unmanured ............... & 3 \\
\hline $2 a$ & Sulphate of ammonia $\left(=25 \mathrm{lbs} . \mathrm{NH}_{3}\right) \ldots \ldots \ldots \ldots$ & - * \\
\hline $2 a a$ & As $2 a$, with 5 cwt. lime, $1905,1909,1910,1912$. & it \\
\hline $2 b$ & $" \quad, \quad 2$ tons lime, $1897,1912 \ldots \ldots \ldots \ldots \ldots$ & 8 \\
\hline 260 & " $" \quad " \quad, \quad 1897,1905,1912 \ldots \ldots \ldots \ldots \ldots \ldots \ldots \ldots \ldots \ldots \ldots \ldots \ldots \ldots \ldots \ldots$ & 6 \\
\hline $\begin{array}{l}3 a \\
3 b\end{array}$ & Nitrate of soda $\begin{aligned}\left(=50 \mathrm{lbs} . \mathrm{NH}_{3}\right) \\
(=25 \mathrm{lbs} .\end{aligned}$ & $\begin{array}{r}10 \\
8\end{array}$ \\
\hline 4 & Mineral manures (3 cwt. "super" and $\frac{1}{2}$ cwt. $\left.\mathrm{K}_{2} \mathrm{SO}_{4}\right) \ldots \ldots \ldots \ldots \ldots \ldots$ & 3 \\
\hline $\begin{array}{l}5 a \\
5 a a\end{array}$ & 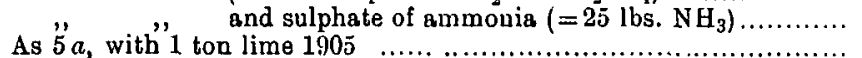 & $-{ }^{\dagger}+$ \\
\hline $\begin{array}{l}5 a a \\
5 b\end{array}$ & 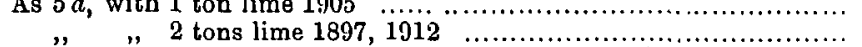 & $\begin{array}{l}6 \\
7\end{array}$ \\
\hline 6 & Mineral manures and nitrate of soda $\left(=25\right.$ lbs. $\left.\mathrm{NH}_{3}\right) \ldots \ldots \ldots \ldots \ldots \ldots \ldots \ldots$ & 5 \\
\hline & 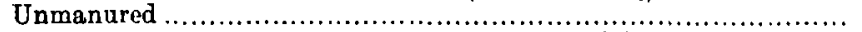 & 5 \\
\hline $8 a$ & $\begin{array}{l}\text { Mineral manures, aud in alternate years, sulphate of ammonia } \\
\qquad\left(=50 \mathrm{lbs} . \mathrm{NH}_{3}\right)(1911)\end{array}$ & -+ \\
\hline $8 a a$ & 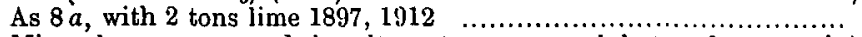 & 8 \\
\hline $8 b$ & $\begin{array}{l}\text { Mineral manures, and in alternate years, sulphate of ammonia } \\
\left(=50 \mathrm{lbs} . \mathrm{NH}_{3}\right)(1912)\end{array}$ & -1 \\
\hline $8 b b$ & 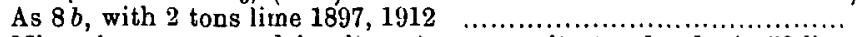 & 9 \\
\hline $9 a$ & $\begin{array}{l}\text { Mineral manures, and in alternate years, nitrate of soda (=50 lbs. } \\
\left.\mathrm{NH}_{3}\right)(1911)\end{array}$ & \\
\hline $9 b$ & $\begin{array}{l}\text { Mineral manures, and in alternate years, nitrate of soda (=50 lbs. } \\
\left.\mathrm{NH}_{3}\right)(1912)\end{array}$ & 6 \\
\hline $10 a$ & "Super" 3 cwt. and nitrate of soda (=25 lbs. $\mathrm{NH}_{3}$ ) $\ldots \ldots \ldots \ldots \ldots \ldots \ldots$ & 5 \\
\hline $10 b$ & 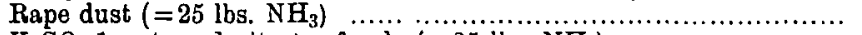 & 5 \\
\hline $11 a$ & $\mathrm{~K}_{2} \mathrm{SO}_{4} 1$ cwt. and nitrate of soda $\left(=25 \mathrm{lbs} . \mathrm{NH}_{3}\right) \ldots \ldots$ & 5 \\
\hline $11 b$ & 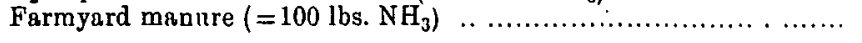 & 4 \\
\hline
\end{tabular}

* No crop. † Observations accidentally omitted.

On the whole perhaps the field plots do not show such decisive results as was expected from a consideration of the water- and potcultures. But it must be remembered that in dealing with such plots which have received the same treatment for many years other factors come into play besides the direct effect of the manure on the plant. 
Some of the irregularities in the results may be brought about by the different chemical and physical conditions existing in the soils of the various plots as a result of the continuous abnormal treatments they have received. Thus the immediate effect of the inanure on the plant is possibly counterbalanced by some of these other factors which cannot be estimated.

The conclusions which can at present be drawn from these investigations may be shortly summarised as follows :

Susceptibility to mildew and yellow rust in wheat, and to mildew in barley, is increased by providing the plants with large unnounts of available nitrogen: anmonium sulphate and sodium nitrate seem to be equally effective in this direction.

Mineral manures, especially potash salts, on the contraly decrease the susceptibility to disease but cannot counteract the effect of large quantities of nitrogenous manures.

Plants which are semi-starved as regards nitrogen exhibit a considerable degree of imınunity, even if the phosphates and potash are also present only in small quantities.

Lithium salts are also effective in producing immunity, while nitrates of lead and zinc, particularly the latter, render plants extremely susceptible. Other salts of lead and zinc have very little effect on the susceptibility of plants.

A variety of wheat which is almost immune to a disease (such as Little Joss to yellow rust) tends to retain its immunity even when supplied with excess of nitrogenous food-material.

Iucreased immunity does not appear to be due to a lack of foodmaterial available for the fungus in the host, as suggested by $M$. Ward, becanse the plants rendered relatively immune by adding phosphates or potash to their food-supply were as healthy and well-grown as those receiving no such additions.

It yet remains to be seen what physiological explanation can be found to account for the changes in susceptibility which can be produced in plants by the above means. 